\title{
The Organizational Communication Perspective Theory
}

\author{
Kristina $^{1^{*}}$ \\ ${ }^{I}$ Sahid Univesity of Jakarta, Jl. Prof. DR. Soepomo, Jakarta, and 12870, Indonesia
}

\section{ARTICLE INFO}

AIJ use only:

Received date : 10 June 2020

Revised date : 20 June 2020

Accepted date : 01 July 2020

\section{Keywords:}

Organization Communication

Internal

External

\begin{abstract}
A B S T R A C T
Public sector organizations are undergoing a transformation in management style. Not only is the behavior of government agencies increasingly being carried out like business, where managers play a central role, but aspects of client service are also becoming more important. Communication is input or message from one person to another. Organizations need communication to streamline their work and carry out tasks in a perfect way. Communication is the art of sending messages and receiving the same in the form of feedback. The success of an organization is highly dependent on effective organizational communication patterns. This study aims to understand communication in achieving the objectives of government organizations. Furthermore, this study discusses effective communication in government organizations.
\end{abstract}

\section{INTRODUCTION}

The dynamics of an organization that is always alive and the climate is always developing is characterized by good organizational communication. Actualization of good climate, namely the creation of active and effective communication between management and subordinates, between subordinates and colleagues, subordinates, and leadership in the community in an organization. The creation of the climate is expected to accelerate various coordination, cooperation and achievement.

Policy is a thing that always exists in every organizational life, there is no organization that does not have a policy, it is because the policy is a basic guideline of the running process

\footnotetext{
* Corresponding author.

E-mail address: nurhayatikristina8@gmail.com

Article with open access under license
}

of an organization, so that the organization can run properly. But the policy in an organization is sometimes sensitive, it is because the policy intersects with many people, not infrequently the policies in an organization can cause disappointment on the one hand, while on the other hand it gives pleasure. Organizations or companies are required to be able to solve these problems. Therefore an organization in addition must be able to issue appropriate policies.

with organizational goals, as well as acceptable to all parties related to the organization. The organization must also be able to convey the policy through good communication, so that what is desired by the organization through the policy can be conveyed to those concerned in accordance with what the organization really wants

But in reality there are objects that must be observed empirically showing that the scope 
of the government in Indonesia in the implementation of the communication climate of organizational culture and organizational communication shows symptoms that have not been effective. An example of observations and interviews conducted on leadership and some staff saw a gap between leadership miscommunication with subordinates, subordinates to superiors between work units. Structurally, government organizations led by heads of departments, assisted by groups of structural and functional positions have created a climate of good organizational communication.

In fact there are still often found various problems in carrying out basic tasks and functions to promote the organization. Problems often arise when communication errors.

occurs (mis-communication), between vertical leadership and structural and functional positions as subordinates. Communication errors also often occur horizontally between functional and functional positions (subordinate to each other) in carrying out various programs and activities of the organization. Including communication errors also often occur between diagonal leadership with structural / functional groups and the community relating to the implementation of organizational activities. For example vertically, the head of a department with a structural and functional office group sometimes disagrees in the implementation of basic tasks and functions. Horizontally, fellow subordinates in the implementation of programs and activities often conflict in opinion. Diagonally between leadership,

Organizational communication errors often occur resulting in a decrease in employee performance and achievement in carrying out basic tasks and functions correctly. In an effort to create an effective organizational communication communication climate is needed by growing various actions or communication activities between parties who often communicate in an organization. Realization of the usual communication activities is to always talk, discuss, meet and cooperate in discussing various programs and activities related to the implementation of work tasks carried out.

This is manifested in everyday reality in the Indonesian government, organizational communication climate is often ineffective, because leaders often force communication that is difficult to implement and translate by structural and functional positions because the frequency and effectiveness of communication are not properly socialized. The communication climate is also often ignored among structural and functional groups when discussing various programs and activities. In this group, it is less likely to communicate, less effective in communicating well in private, and group work units, so that errors often occur in carrying out the basic tasks and functions of each program and the assigned activities.

The leadership factor can be a barrier to climate creation and support organizational communication. Leadership becomes a supporting factor that is able to create an effective and harmonious communication climate by always communicating to solve organizational problems. When leadership is unable to solve problems and rarely communicates problems to group structural and functional positions regarding basic tasks and functions, it will become a barrier factor.

Another factor in the behavior of human resources or employees is a factor that supports the creation of climate communication organizational barriers. Employee behavior becomes a supporting factor when employees have competence in communicating organizational problem solving and employee behavior becomes a barrier when employees do not have professional behavior in working in an organization that requires communication.

Working group factors can be a factor inhibiting the creation of an organizational communication climate. When working groups communicate with each other and work together to carry out basic tasks and functions, the organizational communication climate will be harmonious and effective, conversely, if the working groups lack communication, the organizational communication climate is not realized effectively.

External factors including constituent organizations can be a barrier to creating a good organizational communication climate. External factors are expected to be played by organizations to encourage communication and cooperation that is well established with various parties, stakeholders or the community to be a supporting factor that will create effective communication. Conversely, if external factors often experience 
communication errors or lack of communication frequency, then the application is not made with good communication and this is a factor that limits the creation of a good organizational climate in communication.

\section{THEORY/CALCULATION \\ Organizational Communication}

The word "Communication" comes from the Latin, "comunist", which means making a community or building friendships between two or more people. The word "communis" is "sharing" which means communico (Stuart, 1983, in Vardiansyah, 2004: 3). Other literature mentioned in communication also comes from the word "communication" or "communicare" which means "to make the same" (to make common). The term "communis" is the term most often referred to as the origin of the word communication, which is the root of the same Latin word communication indicating that thoughts, meanings, or messages about personal religious beliefs are the same. (Http: //cahpct.blogdetik. com / 2019/04/02 / definitioncommunication /).

From the description above it can be concluded that communication originates from the root word which means always (1) involves the exchange of verbal and nonverbal symbols or signs, (2) a harmonious togetherness relationship between communicator and communicant. Verbal symbols or signs as spoken and written languages. While nonverbal signs such as symbols or imitating, movement and sound. A harmonious togetherness relationship is not always the same as a positive relationship as intimacy or intimacy, but the formation of a contact relationship between the sender of the message and recipient of the message through certain symbols or signs that are verbal or nonverbal. This application is a symbol of good contact made by yourself (sometimes Intrapersonal) and also with other parties (interpersonal).

Human life in the world cannot be eliminated from organizational communication activities as an integral part of the system and order of the social life of humans and society. Communication activities can be seen in every aspect of everyday human life, from humans to waking to sleep at night. Of course most of the activities of life using good communication are nonverbal and verbal communication. However, what is meant by communication itself.
Sendjaja (2009: 12) tries to define organizational communication as a process by which messages move or pass (through channels) from source to receiver with the aim of changing behavior, changes in knowledge, attitudes and excessive or more behavior. At least four main elements found in the communication model are source (source), message (message), channel (channel) and receiver (receiver).

Wilbur Schramm (1995: 212) states organizational communication as a process of sharing (sharing processes). Schramm decided that communication came from the Latin word (language) which means common or shared. When communicating, actually trying to foster togetherness (commonnes) with someone. Humans try to share information, ideas or attitudes. For example, trying to communicate with readers to convey the idea that the nature of communication is an attempt to make the recipient or giver of communication have the same understanding with the specified mailbox (Suprapto, 2006: 2-3).

Before looking at the implementation of organizational communication approaches applied in government related to policy delivery, researchers dissected in advance about the six organizational communication approaches, first the classic approach, according to Katherine Miller in terms of communication content is: "The content of communication in these organizations is restricted to work-related issues. In the classical theories we have considered, there are certain things that should be talked about and certain things that should not be talked about in the organization. "(Miller, 2012: 30). (The communication content in these organizations is limited to work-related issues. In the classical theories we have discussed, there are certain things that must be discussed and certain things that must not be discussed in the organization). Based on the above explanation that the communication content carried out in organizations in this classic approach is limited to the problem of tasks and work in the organization. In this classic approach emphasizes that there is something that needs and something that does not need to be discussed in the organization. This principle shows that employees must focus on the goals of the organization, not on their own individual needs and desires.

The direction of communication in the classical approach according to Katherine Miller is: "In these classical theories, the vast majority of 
communication in the organization flows downward in the form of orders, rules, and directives (Miller, 2012: 30). (in this classical theory, most of the communication in organizations flows down in the form of orders, rules and instructions). Based on this explanation, it is stated that in the classical approach the communication direction in the organization is mostly vertical from top to bottom which is usually in the form of orders, rules, and direction from the organization's leadership to the members of the organization. In this classic approach it is very rare to find communication in organizations that are not related to the task.

The communication channels used in the classical approach according to Katherine Miller are as follows: "classical theories emphasize the permanence of rules and procedures for efficient organizational functioning, these organizations will probably also rely heavily on written communication in the form of employee handbooks, instructions, mission statements, rules, and performance evaluations (Miller, 2012: 31). (classical theories emphasize the immutability of rules and procedures for the organization's efficiency function, these organizations will probably also depend heavily on written communication in the form of employee handbooks, instructions, mission statements, rules, and performance evaluations). Based on these explanations it can be interpreted that communication channels in the classic approach are usually written as in the form of employee handbooks,

Communication style in this classic approach according to Katherine Miller stated that: "We have already noted that communication will tend to be top-down, written, and task-related. It is also likely that the tone or style of that communication will be highly formal. For example, forms of address will often be distant rather than familiar (for example, Mr. and Ms. Rather than first names). Titles will be used (such as supervisors, secretaries, or administrative assistants) to separate managers from other employees. The vocabulary chosen for messages will avoid slang and colloquial terms, opting instead for highly standard language "(Miller, 2012: 31). (We have emphasized that communication will tend to be top-down, written with related tasks. It is also possible that the tone or style of communication carried out will be very formal. For example, the form of reprimand will often be far from the friendly reprimand (for example, Mr. and Ms.
Rather ... then the name), a position will be used (such as a supervisor, Secretary, or Administrative Assistant) to distinguish managers from other employees. The vocabulary chosen to communicate will avoid everyday terms, choosing the opposite for very standard language). Based on these explanations it is stated that communication styles will tend to be formal such as calling and greeting with the utmost respect like fathers, mothers. Then it can also be given a title in communicating to distinguish between superiors and subordinates. or Administrative Assistant) to distinguish managers from other employees. The vocabulary chosen to communicate will avoid everyday terms, choosing the opposite for very standard language). Based on these explanations it is stated that communication styles will tend to be formal such as calling and greeting with the utmost respect like fathers, mothers. Then it can also be given a title in communicating to distinguish between superiors and subordinates. or Administrative Assistant) to distinguish managers from other employees. The vocabulary chosen to communicate will avoid everyday terms, choosing the opposite for very standard language). Based on these explanations it is stated that communication styles will tend to be formal such as calling and greeting with the utmost respect like fathers, mothers. Then it can also be given a title in communicating to distinguish between superiors and subordinates.

Human relations approach can be interpreted as human relations or human relations, in organizations, this human relations theory emphasizes the importance of individuals and social relations in organizational life. Humans as members of organizations are the core of social organizations, humans are involved in organizational behavior. Without humans, organizations would not exist, therefore human factors in organizations must receive attention and cannot be ignored as is the case with classical theories (Arni, 2011: 39). Based on the explanation above, it can be interpreted that in an organization it is not merely that it only requires regulations, bureaucracy, and division of tasks as outlined in the classical approach, however, a more human approach to the organization also becomes very important, because whatever is carrying out activities in the organization is human. Therefore social relations or human relations within the organization also have an important function in the smooth running of the 
organization as mentioned in the human relations approach.

Regarding communication in this human relations approach to the content of its communication stated that: "In human relations organizations, task-related communication still exists, but it is accompanied by communication that is attempted to maintain the quality of human relations within the organization - maintenance communication" (Miller , 2012: 51). (In human relations organizations, communication-related tasks still exist, but this is accompanied by communication that seeks to maintain the quality of human relations in the organization - maintenance of communication). The explanation from the above quote can be explained as follows, namely the human relations approach in organizations regarding the content of communication, although there is a similar to the classical approach, namely regarding communication that is intertwined because of a task in the organization,

The direction of communication is also stated, that: "A human relations approach does not eliminate this need for vertical information flow but instead adds an emphasis on horizontal communication. As discussed earlier in this chapter, human relations theorists believe that an important aspect of need satisfaction is communication among employees, so interaction that flows horizontally among employees is just as important as downward communication in the accomplishment of organizational goals "(Miller, 2012: 52 ) (The human relations approach does not eliminate the importance of vertical information flow but instead adds emphasis to horizontal communication. As discussed earlier in this chapter, human relations theory believes that an important aspect of satisfying communication needs between employees, so interaction that flows horizontally between employees is as important as decreasing communication in achieving organizational goals). The explanation from the quote above is that the human relations approach in organizations regarding the direction of communication is that the human relations approach does not eliminate the need for information direction, namely vertical communication from above, but adds to horizontal communication as well. In the human relations approach, it is believed that communication needs between employees also become an important aspect in addition to downward communication in achieving organizational goals. The explanation from the quote above is that the human relations approach in organizations regarding the direction of communication is that the human relations approach does not eliminate the need for information direction, namely vertical communication from above, but adds to horizontal communication as well. In the human relations approach, it is believed that communication needs between employees also become an important aspect besides communication downward in achieving organizational goals. The explanation from the quote above is that the human relations approach in organizations regarding the direction of communication is that the human relations approach does not eliminate the need for information direction, namely vertical communication from above, but adds to horizontal communication as well. In the human relations approach, it is believed that communication needs between employees also become an important aspect besides communication downward in achieving organizational goals.

The communication channel is also mentioned, that: "In the human relations approach, in contrast, face-to-face communication takes center stage. This channel of interaction allows for more immediate feedback and more consideration of nonverbal cues. Thus, face-to-face communication is more appropriate for addressing the human needs emphasized in the human relations approach "(Miller, 2012: 51). (In the human relations approach, on the other hand, face-to-face communication becomes primary. This mode of communication allows for more direct feedback interactions and also nonverbal cues to be more numerous. Thus, face-to-face communication is more appropriate to address the human needs emphasized in the approach human relations). The explanation from the above quote is that the communication channel is more face to face,

Communication style is also stated that: "A human relations organization is likely to want to break down the differential status between managers and employees as a means of satisfying social needs. Thus, it is likely that informal communication - with less emphasis on titles, "business" dresses, and bureaucratized language — will be emphasized (Miller, 2012: 53). (Human relations organizations want to break the differential status or difference between managers and employees as a means of satisfying social 
needs. So, more informal communication - by reducing the emphasis on position). In the above quotation it can be explained that the communication style is in contrast to the classical approach which is more towards formal communication that takes into account the standards of politeness and professionalism,

The approach of human resources communication content carried out in the organization discussed in the form of tasks, social and innovation of resources within members of the organization. Then regarding the flow of communication in the approach of human resources according to Miller, namely: "In a human resources organization, the goal is to encourage the flow of ideas from all locations throughout the organization. Thus, in the simplest sense, communication in this organizational approach will include all directional flows - downward, upward, horizontal, and diagonal "(Miller, 2012: 52). (In a human resource organization, the aim is to encourage the flow of ideas from all locations throughout the organization. Thus, in the simplest sense, communication in this organizational approach will cover all directions of downward, upward, horizontal,

The communication channel uses all communication channels. While the communication style according to the miller, namely: "human resources organizations have the dual goals of enhancing organizational effectiveness and fulfilling human needs. On the needs side of the equation, an informal style is most likely to satisfy needs for affiliation. On the organizational effectiveness side, an informal style will also probably serve better than a formal one because employees will probably feel more comfortable contributing in a relatively informal manner (Miller, 2012: 53). (Human resource organizations have the dual purpose of increasing organizational effectiveness and meeting human needs. On the needs side of the equation, informal styles are most likely to meet the needs of affiliates. On the organizational effectiveness side,

This system approach views the organization as a system in which all parts interact and each part influences the others. In this approach, communication makes the system vital and alive. Because if a system has to survive, then all the parts must be coordinated and all activities must be synchronized, so that communication becomes important. Communication will connect various parts with other parts and generate many new ideas (Masmuh, 2010: 43)

A cultural approach is an approach that views an organization as a social or cultural unit. The cultural approach sees the organization and its workers having the same set of values and goals (Masmuh, 2010: 43). In this cultural approach, culture in organizations is considered as a tool to achieve organizational effectiveness. However, members of the organization will not necessarily follow the culture that is in the organization, members of the organization in acting to choose based on their beliefs, values and processes. Therefore the organization must have the ability to persuade its members to have similarities in matters that exist in the culture of the organization. Thus the goals of the company / organization can be realized effectively.

Critical approach is an approach that emphasizes the organisation's goal of raising voices that are marginalized within an organization. In this critical approach the issues that arise as mentioned by Katherine Miller (2012) are: (1) Certain social structures and processes lead to fundamental imbalances of power, (2) These imbalances of power lead to alienation and oppression for certain social classes and groups , (3) The role of critical theorist is to explore and uncover these imbalances and bring them to the attention of the oppressed groups. It was stated that the issues in critical theory involved (1) certain social structures and processes caused an imbalance. (2) This imbalance of power causes alienation and oppression for certain social classes and groups.

In the previous research, the approach used to see the leadership organization's communication in conveying a policy or information to subway using a top-down communication approach that refers to the concept of Clampitt, DeKoch, and Cashman in Miller (2012: 185)which explains the top-down communication strategy. While the research to be conducted by researchers is to see the leadership of organizational communication in delivering a policy using the organizational communication approach according to Miller, because researchers assume that the delivery of policies is not enough to be seen just by looking at communication from the top down, but it is necessary to look at also like the content of the communication, communication channels and communication style. 


\section{Process in organizational communication}

Communication is a very important aspect for organizations that are developing and developing. For an organization whose communication is not effective, it will have an impact on eg communication, making it difficult for the organization to achieve its goals. Communication within organizations is distinguished for external communication and internal communication (Haeruddin, 2006). Communication organization in principle is a form of activity carried out by everyone who communicates in an organization. Usually communication between leaders and subordinates, intercultural communication with colleagues and subordinates of organizational communication with other organizations (Lesmana, 2006).

Communication in an organization is an action carried out by one or more people with whom you communicate how to send, receive messages, inform, make proposals, discuss to produce feedback in generating understanding and general goals. Therefore, organizational communication is inseparable from the existence of interpersonal, interpersonal, small group, open communication or mass communication behavior carried out by leaders and subordinates.

Communication organization is the interrelationship in various development of messages conveyed through the channel of the message source to the recipient of the message. Usually there are parties in an organization as a source of information and recipients as providers of information to produce effective organizational competence in processing messages and channels as feedback and feed forward from the effects of communication in advancing the organization (Spitzberg and Cupach, 2009).

Organizational communication is a motive that causes people to communicate made consciously, which involves a lot of interest in accordance with the effective use of communication media resulting in effective organizational communication inseparable from the existence of internal and external communication. Internal communication can be done vertically, horizontally and diagonally. And external communication is carried out through the provision of information, discussion and collaboration which involves having a conversation using messages that are easily understood (Reardon, 2007).

Internal organizational communication is an activity that involves giving and receiving messages from superiors to subordinates or other people, so that internal, vertical, horizontal and diagonal communication. This form of communication varies according to the form of organizational activities in carrying out effective organizational communication. Naisbitt (2004) states that internal organizational communication that is vertically a communication command of actions, reprimands, praise and instructions of all activities to achieve organizational goals are communicated. Internal organizational communication, namely the horizontal communication law that mediates between leadership, between employees and between work units in organizational activities is discussed in order to achieve goals.

Understand the importance of internal communication organizations that involve subordinate elements of leadership, and work units as part of the communication material to be separate from the organization. Elements of effective communication from internal organizations in communicating organizational problems make it easier for these organizations to solve problems in achieving organizational goals (Rossy, 2008). Further communication for external organizations can be seen in the form of communication between organizational activities including the provision of information on feedback, cooperation and dialogue activities between organizational cultures. Nuhui (2005) states that organizational external communication between organizations in various feedbacks giving information is usually applied to provide materials or materials needed by each organization in facilitating the organization's current activities. In addition to this form of external communication working together in various interests to restructure and complete organizational activities that require individual organizations to mutually dialogue in advancing and solving organizational problems. Dimensions of organizational communication: first, external communication, members of the organization used for interactions with individuals outside your organization. External communication carries the 
message of the organization and the relevant organizational environment. External messaging systems are used to convey information from the organizational environment and to provide environmental information from the organization. And second, internal communication, message patterns are shared (Share) between members of the organization, human interactions that occur within the organization and between members of the organization. As organizations grow in size or complexity or spread beyond regions and time zones, this requires an internal communication program that helps build a team. This means that internal and external organizational communication is important in realizing how communication will be made within the organization to achieve organizational goals. human interactions that occur within the organization and among members of the organization. As organizations grow in size or complexity or spread beyond regions and time zones, this requires an internal communication program that helps build a team. This means that internal and external organizational communication is important in realizing how communication will be made within the organization to achieve organizational goals. human interactions that occur within the organization and among members of the organization. As organizations grow in size or complexity or spread beyond regions and time zones, this requires an internal communication program that helps build a team. This means that internal and external organizational communication is important in realizing how communication will be made within the organization to achieve organizational goals.

\section{Organizational climate in organizational communication}

Organizational climate is one of the things that plays an important role in the life of an organization. Organizational climate consists of perceptions of organizational elements and the influence of these elements on the organization. Redding (1972) states that organizational communication climate as a quality of experience is the goal of an internal organizational environment that includes perceptions of organizational members' messages and message relationships with events that occur within the organization.
According to the organizational communication climate Soemirat et al (1999: 85 ) is a function of activities that shows that members of the organization to trust and provide freedom to take risks, encourage and give responsibility in carrying out tasks, provide open and sufficient information about the organization and listen attentively and get reliable and frank information from member organizations. Climate communication organization in principle is a form of activity carried out by everyone who communicates in an organization. Usually communication occurs between leaders and subordinates, intercultural communication with colleagues and subordinates of organizational communication with other organizations (Lesmana, 2006).

The climate of communication in an organization is an action taken by one or more people with whom you communicate how to send, receive messages, inform, make proposals, discuss to produce feedback in generating the same understanding and goals. Therefore in climate communication organizations apart from the existence of non-personal communication, interpersonal, small groups, open or mass communication behavior carried out by leadership and subordinates.

Climate is a condition of organizational communication relationships in various development messages that are conveyed through the message source channel to the recipient of the message. Usually there are parties in an organization as a source of information and recipients as providers of information to produce effective organizational competence in processing messages and channels as feedback and feed forward from the effects of communication in advancing the organization (Spitzberg and Cupach, 2009).

Organizational communication is an objective climate condition of people who communicate made consciously, which involves a lot of interest in accordance with the effective use of communication media resulting in an effective climate of communication organizations cannot be separated from the existence of internal and external communication. Internal communication can be done vertically, horizontally and diagonally. And external communication is done through the provision of information, discussion and 
collaboration that involves the existence of talks by using messages that are easily understood (Reardon, 2007).

According to Alo in Sedarmayanti (2018: 66-67), in the process of organizational communication, there are important components to consider, namely: Internal, external, top-down, bottom-up (vertical), horizontal, diagonal and network communication lines. Here is a picture of communication based on organizational structure.

\section{Picture 1}

Organizational Communication Based on Organizational Structure.

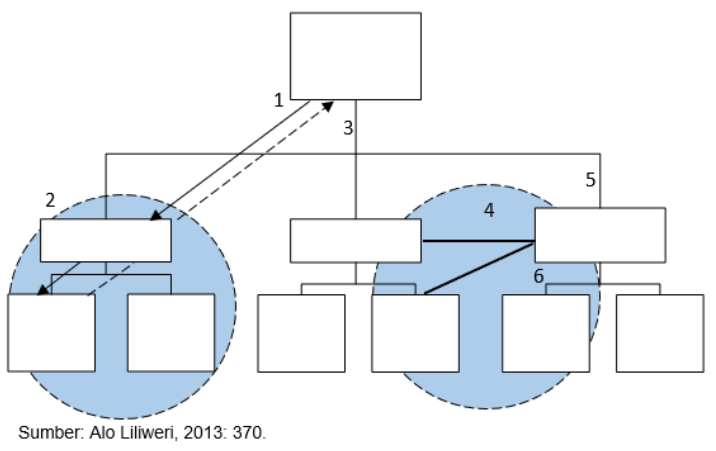

Information:

1. Command line - vertical communication (the relationship between superiors and subordinates).

2. One work unit with similar tasks and functions.

3. Vertical communication lines of responsibility (superior and subordinate relationships).

4. Horizontal communication (the relationship between two officials who have the same position / level).

5. One click unit (informal unit formed by relationships between several people from different position levels.

6. Diagonal communication (the relationship between two officials who come from different work units and have different levels / positions).

The picture shows how the organizational communication process follows the organizational structure with horizontal and diagonal command lines of communication responsibility to accommodate relationships between jobs that functionally require coordination. In organizational practice, there are also two forms of networking, formal and informal networks.

\section{Supporting and Limiting Factors}

There are four factors that support and hinder organizational communication climate according to Higgins (1994: 477-478), namely leadership, human behavior, work groups and external organizations. Further details are described as follows:

Basically every action taken by organizational leadership in the communication climate influences several things such as rules, policies and procedures relating to organizational problems related to personnel issues, the distribution of rewards, communication styles, ways used to motivate, techniques and disciplinary actions, interactions between management and groups, group interactions, attention to the problems that human resources have over time, as well as the need for human well-being and satisfaction.

Human behavior affects the organizational climate through the communication personality displayed, especially the needs and actions taken to meet those needs. Communication between human resources plays an important role in shaping the climate. The way a person communicates determines the degree of success or failure of human relations. Based on a person's normal style of life or regulating something, it can add to it being a positive climate or it can also reduce to being negative.

Working groups, in this case there are special needs for most people in terms of friendly relations, a requirement that is often satisfied by groups in organizations. The group develops in two ways namely formally, especially in working groups and informal groups as friendship or mutual interest.

The influence of the external organizational communication climate views the state's economic organization as the main factor influencing the climate. As pressure to increase profits, government policy in setting rules and determining wages.

\section{Theoretical Framework}

Based on the explanation of the previous theory, the conceptual framework as a way to describe the things that are the focus of thought in this study. In principle, there are two things that are the focus of organizational studies and organizational communication. Referring to 
the theory postulated by Effendy (2009: 66) which states that the success of an organization is determined by the ability of each individual to communicate their activities in achieving goals. The most important communication in an organization includes internal and external communication.

Forms of organizational communication are grouped into two internal and external organizational communications. Internal organizational communication is communication that occurs in the organizational communication environment including vertical, horizontal and diagonal communication. Communication of external organizations in the form of providing information, collaboration and dialogue with various parties from one organization by another organization. Increasingly intensive and active from each party that carries out organizational communication, provides a close relationship with an increasingly conducive and profitable corporate climate. This is a consideration to see whether real organizational communication is implemented by each party involved and see the relationship between organizational communication. On the basis of this conceptual framework, the researchers pour as follows :

Figure 2

\section{Framework}

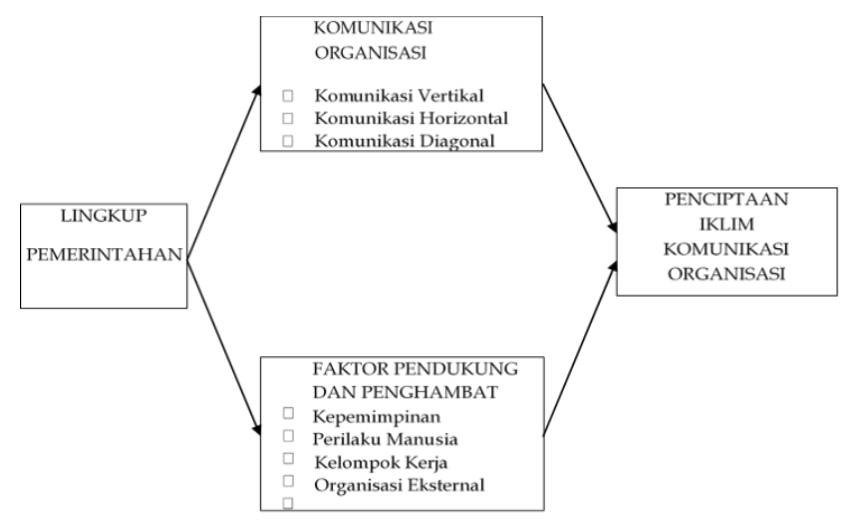

\section{METHOD}

The approach used in this study is a qualitative approach, a qualitative approach that is an approach as a research procedure that produces descriptive data in the form of written or oral words from people and observable behavior (Moloeng, 2002). While this type of research uses descriptive research, which describes or analyzes a research result but is not used to make broader conclusions (Sugiyono,
2009). The subject of this research was conducted at the government in Indonesia. The type of data used in this study is primary data is data collection is done by direct interviews with competent authorities.

In determining the research subject is preceded by the determination of key informants, paving the way for this research. Key informants are people who have the most authority in determining the policies that must be implemented in connection with organizational communication in the climate of governance in Indonesia. The person who is the main key to get primary data, because with the consideration that the person who made the key informant is more aware of the problem being examined. Furthermore, key informants assist researchers in determining predetermined research subjects, because key informants know more people who can provide the data needed by researchers to discuss problems in this study. In this study, to analyze the data collected using qualitative data analysis techniques.

\section{RESULTS AND DISCUSSION}

Organizational communication is applied to the Indonesian government through vertical, horizontal and diagonal communication. In principle, vertical communication made to the government in Indonesia is communication between leaders and subordinates of work units, in the form of messages, orders, reprimands and solutions. The principle is applied to horizontal communication between leaders and subordinates of work units, in the form of communication based on work activities that are input, processing and output that have been communicated. While the principles applied to diagonal communication are carried out by involving all elements of the communication organization to solve organizational problems through the organization of internal communication.

The vertical implementation of communication organizations from several activities carried out by the head of work units and subordinates to be communicated through messages, orders, solutions and various strikes carried out by work units and their subordinates. Leadership calls on all work units and staff to 
communicate issues that are relevant to the implementation of basic tasks and functions.

The results of horizontal internal organizational communication between leaders, work units and subordinates are implemented on target. For this reason, leadership in directing subordinates or employees can design activity plans as guidelines in carrying out tasks, distributing and giving instructions for the implementation of subordinate tasks so that their implementation runs smoothly. Further distribution and instructions on the implementation, monitoring, supervision and evaluation of the implementation of tasks and activities of subordinates.

Further communication for internal organizations diagonally is applied by involving all elements in various activities and work programs. Dioagonal organizational communication as the implementation of the implementation of basic tasks and functions of each unit as communicated to each work unit leader and subordinates to support the task.

Horizontal internal organizational communication has been applied by conducting communication that involves the leadership of the work unit in instructing each range of commands, especially those relating to the implementation of basic tasks and functions to carry out various programs and activities involving each work unit.

\section{Diagonal internal organizational communication has been applied to} communicate with all elements of the organization ranging from leadership, work units and subordinates to communicate various matters relating to the implementation of the tasks and functions of each work unit. This communication is carried out to assist the implementation of tasks carried out by the head office and other work units.

The implementation of organizational communication policies has been applied vertically, horizontally and diagonally. The implementation of vertical communication is implemented through work development, which is vertically communicated namely program implementation, improvement and improvement of facilities and infrastructure. Understanding organizational internal communication basically understands how organizational communication is carried out in delivering messages and receiving messages involving elements that communicate within the organization, leadership, work teams and subordinates.

Internal organizational communication involving leadership, work units and subordinates, vertically is a source of communication messages given by the leadership to the work unit, then managed by subordinates to produce information messages, orders, reprimands and solutions in carrying out organizational activities. The following internal organizational communication schemes are displayed vertically below :

\section{Figure 3}

Vertical internal organizational communication

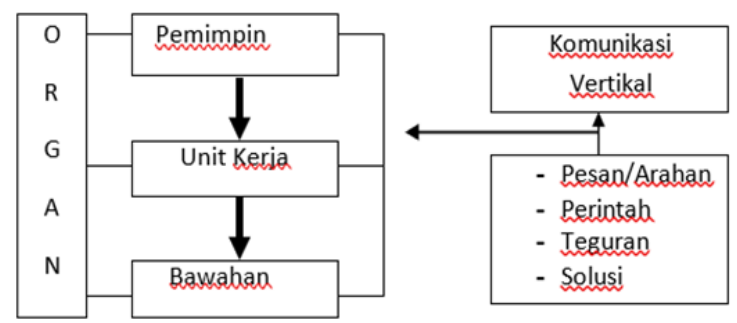

Internal organizational communication applied by each element of the organization is a concern and consideration in order to understand the significance of communication applied in an organization. Internal communication that is established is very effective, making it easier for every element in the organization to achieve progress and achieve goals. Effective internal organizational communication, i.e. all components of organizational involvement ranging from leadership, subordinate work units to each other in providing information and managing messages to achieve goals. Means of organizational communication are important instruments for organizational success.

The success of an organization is inseparable from the importance of the organization's external communication applied. The application of external communication is built on the existence of reciprocal communication. External communication is manifested as a form of providing reciprocal information, cooperation and organizational dialogue activities. In managing an organization a leadership action is needed to take policy in communicating with external parties or external organizations. This is intended to build an active communication relationship between two or 
more organizations that communicate. Realization of external organizational communication that communicates more than one form of interest or needs of one organization with other organizations.

In principle, an organization that has active communication with other organizations to exchange information, establish cooperation and dialogue will be able to solve problems together. Image of an external organizational communication, namely the effective interests, cooperation and objectives to be achieved. Through communication between organizations will result in the achievement of goals based on interests and needs. DeVito (2011) states that communication channels are important for organizations to achieve organizational goals. This means that an organization that implements external organizational communication is basically based on three aspects that will be achieved, namely: 1) communicating to achieve interests, 2) communicating with leaders, and 3) communicating to achieve goals.

Organizational success based on organizational external communication always gives priority to the formation of effective communication through the exchange of information between organizations, behaviors or partnerships in various affairs or programs as well as conducting discussions through dialogue or simulations to solve differences between organizations.

Through external organizational communication, each component of the work unit of the organization, leaders and subordinates, is able. Effective communication is communication through cooperation between the two organizations that is maintained based on the existence of intensive, progressive, transparent and accountable communication. External organizational communication is often carried out by several organizations, such as interfaith dialogue in organizational activities. This dialogue communication activity can be done through communication between leaders, between work units and between subordinates or can be done en masse through seminars, meetings, or matters relating to the need to communicate the two organizations that are usually carried out according to the Agreement.

Management often has problems not communicating effectively. When effective communication is very important for managers, there are at least two reasons, first, communication is the process by which management functions ranging from planning, organizing, directing and monitoring can be achieved; Second, communication is an activity where leaders spend a large proportion of their time

\section{CONCLUSION}

\section{Conclusion}

Based on the results of research and discussion, it was concluded that the organizational communication practices applied to the Indonesian government had been communicated by the head with the work unit and subordinates in carrying out the basic duties and functions in assisting the leadership task. The application of organizational communication to create an organizational climate is applied vertically, horizontally and diagonally by the head of the work unit and innate in the organization to carry out the policies, basic tasks, and functions assigned.

The implementation of the communication policy of government organizations in Indonesia cannot be separated from supporting and hindering factors. This factor is a factor of leadership, resource behavior, work groups and external organizations. Being a supporting factor, if the leadership continues to communicate each program and activity to subordinates, employees as a means of communicating with each other for the smooth running of tasks, so that the work groups can coordinate with each other and always have good communication with various stakeholders outside the organization. Be a barrier when leadership, employees, work groups and external organizations show an attitude of individualism, not communicating with each other in the implementation of activities in an organization.

\section{Suggestion}

In the context of implementing communication policies of government organizations in Indonesia, researchers provide suggestions that they need to be improved and the application of organizational communication to avoid mistakes in communicating policies and implementing their respective basic tasks to create a conducive communication climate for government organizations.

Need to be improved and maintain an understanding of the importance of 
communication in government organizations in Indonesia in order to carry out programs and activities that have been communicated, vertically, horizontally and diagonally. And this paper is a reference for further researchers regarding organizational communication in other research objects.

\section{REFERENCES}

1. Arni Muhammad. 2011. Organizational Communication. Jakarta: Earth Literacy

2. Cresswell, John W (2014). Research Design Qualitative, Quantitative and Mixed Approaches, Translated by Achmad Fawaid. Yogyakarta: Student Library

3. DeVito, Joseph A., 1989, Communication between people (fifth edition), Professional Books, Jakarta

4. Effendy, Onong Uchjana, 2009. Communication Theory and Practice, Bandung: Youth Rosdakarya.

5. Haeruddin, 2006. Communication and Communication. Publisher Rajawali Press, Jakarta. Carrot, Tubbs, SL, 2005, Human Communication, Fourth Edition. Random House Inc. New York.

6. Higgins. 1994. The Relationship Between Leadership and Organizational Climate and Job Satisfaction. Terj Abdul Rasyid and Ramelan. PPM. Jakarta.

7. Kraft, A., Sparr, L., \& Peus, C. 2018. Giving and making a sense of change: The back and forth between leaders and employees. Journal of Business Psychology.

8. Keyton, Joann. 2017. Communication in Organizations. Annual Review of Organizational Psychology and Organizational Behavior.

9. Lesmana, Mulyana, D, 2006, An Introduction to Communication Studies, 6th Edition, Rosdakarya, Bandung.

10. Luo, Y., \& Jiang, H. (2014). Effective public relations leadership in organizational change: A study of multinationals in mainland China. Journal of Public Relations Research.
11. Masmuh, Abdullah (2010). Organizational Communication in Perspective of theory and practice. Malang: UMM Press

12. Macnamara, Jim. 2016. The Work and 'Architecture of Listening': Addressing Gaps in Organization-Public Communication. International Journal of Strategic Communication.

13. Magnus, Fredriksson \& Josef Pallas. 2016. Diverging Principles for Strategic Communication in Government Agencies, International Journal of Strategic Communication

14. Miller, Katherine (2012). Organizational Communication Approaches and Processes. United States: Wadsworth Cengage Learning

15. Moleong, Lexy. (2002). Qualitative Research Methodology. Bandung: PT. teen Rosdakarya

16. Naisbitt, Marethen, Jr., 2004. Communication in Definition of Concept. Published by John Wiley and Sons, New York.

17. Nuhui, Muspida, 2005. Application of Communication and Effective Forms of Communication. Publisher Dian Sarana, Surabaya.

18. Nurudin Tannen, 2004, The Art of Effective Communication: Building Relationships by Fostering a Conversation Style, (language transfer from Amitya Komara), PT Gramedia Pustaka Utama, Jakarta.

19. Pace, Don R. Wane, and Faules, F, 2001. Communication Organization. Published by John Wiley and Sons, New York.

20. Purwanto, Andrik., 2006. Multicultural Communication. 1st printing. Surakarta

21. Reardon Berlo, SA, SJ 1987. Interpersonal Communication, Relating to Others, Allyn and Bacon. Boston.

22. Redding, W. Charles. 1972 Communication with the Organization: Interpretive review of theory and research. New York. Industrial Communication Council 
23. Rossy, Harold, 2008, Theories Of Human Communication, Fifth Edition, Wadsworth Publishing Company, California.

24. Ruslan, AF, 2002. Management, Erlangga, Jakarta.

25. Sadia, Aysha \& Mohd, Berhannudin \& Kadir, Zulida \& Sanif, Sazuliana. 2016. The Relationship between Organizational Communication and Employees Productivity with New Dimensions of Effective Communication Flow. Journal of Business and Social Review in Emerging Economies.

26. Sarwoto, Adi, 1999. Organizational Sociology, Citra Aditya Bakti, Bandung.

27. Schramm Wilbur, 1995. The Process Effect of Mass Communication, University of Illinois Press Urbana

28. Sendjaja, Sasa Djuarsa, 2009. Introduction to Communication. Jakarta: Open University.

29. Sedarmayanti, Government Communication. 2018. Bandung: PT. Refika Aditama.
30. Suprapto, Tommy, 2006. Introduction to Communication Theory. 1st printing. Yogyakarta: Media Pressindo.

31. Sutarto, 2004. Human Aspects in Organizations, Erlangga Publisher, Jakarta.

32. Soemirat, Soleh, Ardianto, Elvinaro and Suminar, Yenny. Organizational Communication. PT. Gramedia Main Library. Jakarta: 1999

33. Sugiyono, 2009, Quantitative, Qualitative and R\&D Research Methods, Bandung: Alfabeta

34. Spitzberg, Danielson and Cupach, T, 2009. Communication Model and Practices. Published by Prentice Hall, New York.

35. Vardiansyah, Dani, 2004. Introduction to Communication Studies. 1st printing. Bogor: Ghalia Indonesia.

36. Walber, John, 2006, Theories of Human Communication, Belmont, California: Wadsworth Publishing Company.

37. Yumi, Wiryanto, 2006, Introduction to Communication Studies, Jakarta: PT RajaGrafindo Persada 